\title{
SAFESIDE: A computer-aided procedure for integrating benefits and costs in roadside safety intervention decision making
}

Carlos Roque*, João Lourenço Cardoso,

Laboratório Nacional de Engenharia Civil, Departamento de Transportes. Núcleo de Planeamento, Tráfego e Segurança, Av do Brasil 101, 1700-066 Lisboa, Portugal

${ }^{*}$ Corresponding author. Tel.: +351 218443 970; fax: +351 218443 029. Email adress: croque@Inec.pt (Carlos Roque)

Collisions with dangerous roadside obstacles and rollovers are responsible for many injuries and deaths in highways worldwide. International crash data indicate that roadside characteristics contribute to more than half of all run-off-road injury crashes (RORIC) involving serious injury or death. Furthermore, roadside geometric characteristics are believed to be the leading cause of rollover in single-vehicle RORIC. Differences in each country's road network features, car vehicle stock, driving behavior, characteristics of roadside obstacles and economical aspects justify the need for evaluating the merit of specific approaches to roadside safety issues. Results from recent studies carried out at the Laboratório Nacional de Engenharia Civil - LNEC have shown that important differences exist between RORIC in Portuguese roads, when they are compared with RORIC in roads from other countries. A framework was developed for assisting in cost-effective decisions as regards roadside safety interventions, which is based on results from the analysis of registered data and the observation of inservice performance of installed equipments on Portuguese roads. A brief description is provided of cost-benefit analysis software tools for safety evaluation and simulation of roadside scenarios, which were developed at LNEC under a dedicated research project - SAFESIDE-roadside safety. The software contains a list of roadside safety measures (including the present value of their implementation costs and their safety effects) and an accident categorization (based on predictive models for crash frequencies and crash costs). The software is being disseminated by road authorities and relevant technical stakeholders, within the current revision of Portuguese road design standards.

http://dx.doi.org/10.1016/j.ssci.2015.01.001 